\title{
AVALIAÇÃO DA SILAGEM DO HÍBRIDO DE SORGO BR 601 COM ADITIVOS - ALTERAÇÕES NOS TEORES DE MATÉRIA SECA, FRAÇÕES FIBROSAS E DIGESTIBILIDADE “IN VITRO” DA MATÉRIA SECA
}

\author{
ARMANDA COSTA PEREIRA ${ }^{1}$, LÚCIO CARLOS GONÇALVES ${ }^{2}$, ANA LUIZA COSTA CRUZ
} BORGES ${ }^{2}$, JOSÉ AVELINO SANTOS RODRIGUES ${ }^{3}$, SILAS PRÍMOLA GOMES ${ }^{4}$, IRAN BORGES ${ }^{2}$, NORBERTO MARIO RODRIGUEZ ${ }^{2}$, JAIRO JOSÉ COSTA FERREIRA ${ }^{1}$, LUCAS PAIN DELGADO ${ }^{5}$ e MARIANA MAGALHÃES CAMPOS ${ }^{6}$

\author{
${ }^{1}$ Mestre em Zootecnia pela Escola de Veterinária da UFMG, Caixa postal 567, CEP: 30123-970 - Belo Horizontel \\ MG; armandacosta@bol.com.br \\ ${ }^{2}$ Professor(a) da Escola de Veterinária da UFMG, Caixa postal 567, CEP: 30123-970 - Belo Horizonte/MG \\ ${ }^{3}$ Pesquisador do CNPMS/EMBRAPA, Sete Lagoas/MG \\ ${ }^{4}$ Doutorando em Ciência Animal pela Escola de Veterinária da UFMG \\ ${ }^{5}$ Médico Veterinário, Escola de Veterinária da UFMG \\ ${ }^{6}$ Mestranda em Zootecnia pela Escola de Veterinária da UFMG
}

Revista Brasileira de Milho e Sorgo, v.7, n.2, p. 153-163, 2008

RESUMO - Avaliou-se o padrão de fermentação de silagens do híbrido de sorgo forrageiro BR 601 com ou sem aditivos. Foram adotados os tratamentos: silagem sem aditivo (testemunha) e silagens adicionadas com $0,5 \%$ de uréia, $0,5 \%$ de carbonato de cálcio, $0,5 \%$ de uréia mais $0,5 \%$ de carbonato de cálcio e com inoculante bacteriano. Os materiais foram ensilados em silos de "PVC" e abertos com um, três, cinco, sete, 14, 28 e 56 dias de ensilagem. Determinaram-se as variações nos teores de matéria seca (MS), os teores de fibra em detergente neutro (FDN), hemicelulose, celulose, fibra em detergente ácido (FDA), lignina e a digestibilidade "in vitro" da MS (DIVMS). Adotou-se o delineamento inteiramente casualizado, em um esquema fatorial $5 \mathrm{x}$ 7, sendo as médias comparadas pelo teste SNK a 5\%. As silagens tratadas com a associação entre uréia e carbonato de cálcio apresentaram as maiores perdas de MS. Os aditivos não promoveram alterações nos teores de FDN, hemicelulose e celulose e na DIVMS. Ocorreu diferença entre a silagem testemunha e as silagens com aditivo, com a evolução do processo fermentativo, quanto aos teores de FDA e lignina.

Palavras-chave: carbonato de cálcio, forragem, inoculante bacteriano, Sorghum bicolor, uréia.

\section{EVALUATION OF SORGHUM SILAGE WITH ADDITIVES - ALTERATIONS IN DRY MATTER, FIBROUS FRACTIONS AND “IN VITRO” DRY MATTER DIGESTIBILITY}

\begin{abstract}
This work evaluated the fermentation pattern of sorghum silage hybrid BR 601 with and without additives. At ensiling time, silages were enriched with the additives, adopting the following treatments: silages without additive (control), with
\end{abstract}


$0.5 \%$ urea, $0.5 \%$ limestone, $0.5 \%$ urea plus limestone and bacterial inoculant. The materials were stored into PVC silos, opened after 1, 3, 5, 7, 14, 28 and 56 days of ensiling. Alterations were determined in dry matter (DM), neutral detergent fiber (NDF), hemicellulose, cellulose, acid detergent fiber (ADF) and lignin contents and in vitro dry matter digestibility (IVDMD). A completely randomized experimental design was used, in a $5 \times 7$ factorial scheme, and the means were compared by the SNK test at 5\% probability. The silage enriched with urea plus limestone showed highest loss of DM. No difference was observed between silage with additives and control regarding NDF, hemicellulose, cellulose and DMIVD. The additives promoted changes in the ADF and lignin contents.

Key words: bacterial inoculant, forage, limestone, Sorghum bicolor, urea

O uso de forragens na forma de silagem está se tornando cada vez mais comum, como uma alternativa para amenizar o problema de escassez de pastagem, no período de estiagem. As culturas de milho (Zea mays L.) e sorgo [Sorghum bicolor (L). Moench] apresentamse como as mais adaptadas ao processo de ensilagem, por sua facilidade de cultivo, alto rendimento e pela alta qualidade das silagens produzidas (Zago, 1992).

A caracterização agronômica e nutricional dos materiais genéticos disponíveis no mercado é de fundamental importância para se obter uma silagem de alta produção e com elevado valor nutritivo. Segundo Molina et al. (2002), o conhecimento do comportamento dos híbridos de sorgo no campo, do ponto ideal de ensilagem e do padrão de acumulação de matéria seca (MS) e proteína bruta (PB) é importante para a implantação definitiva da cultura do sorgo no país.

O sorgo é uma planta que pode ser comparada ao milho em relação ao seu valor agronômico e nutritivo. Por isso, em termos de exigências e produção, aparece como uma alternativa interessante, sendo mais adaptado à seca, devido à sua capacidade de recuperar- se e produzir grãos após período de estiagem e produzindo mais matéria seca em áreas de solo menos fértil, quando comparado ao milho. O uso do sorgo na forma de silagem é favorecido por essa cultura apresentar bons níveis de carboidratos solúveis (CHOs), baixo poder tampão, conteúdo de MS apropriado por ocasião da época de ensilagem e estrutura física que favorece a compactação no silo (Gonçalves et al., 2005) e o desenvolvimento da fermentação lática (Van Soest, 1994).

Porém, o sucesso da fermentação lática depende de três elementos: um ambiente anaeróbico, substrato adequado para as bactérias ácido-láticas e uma população suficiente das mesmas (Muck, 1988). Se esses fatores forem limitantes, tornam o processo de ensilagem arriscado, pois podem ocorrer perdas de nutrientes por efluentes ou fermentações indesejáveis (McDonald et al., 1991). Dessa maneira, muitas forrageiras necessitam de pré-tratamentos, como o uso de aditivos, para tentar minimizar as limitações do processo e obter uma silagem de boa qualidade. Segundo McDonald et al. (1991), o objetivo fundamental do uso de aditivos é assegurar que as bactérias ácidoláticas dominem a fermentação da forragem. 
As silagens de milho e sorgo, além de nutricionalmente deficientes em nitrogênio, são pobres em cálcio e melhorias no desempenho animal têm sido observadas no uso de silagens nas quais se adicionou carbonato de cálcio e uréia, quando comparadas às silagens em que utilizou somente uréia (McDonald et al., 1991). Dessa maneira, segundo Henderson (1993), a adição de carbonato de cálcio, isoladamente ou associado à uréia, vem sendo estudada como forma de controlar a fermentação e melhorar a qualidade da silagem.

A eficiência do processo fermentativo e, conseqüentemente, a qualidade da silagem depende das bactérias epífitas que são colocadas dentro do silo com a forragem. A população de microrganismos epifíticos, entre eles as bactérias produtoras de ácido lático, pode ser naturalmente pequena nas forragens, sendo afetada pelas condições ambientais (umidade, temperatura, radiação solar, espécie e características da planta). Essa grande variação pode levar, ao longo do tempo, à obtenção de silagens de qualidade variável, a partir de um mesmo tipo de forragem e sistema de manejo, tornando interessante a adição de inoculantes bacterianos (Pedroso et al., 2000).

Além de um processo fermentativo inadequado, outros fatores podem acarretar perdas durante o período de ensilagem. As perdas de energia durante a ensilagem ocorrem de diversas formas, principalmente pela respiração da planta, fermentação anaeróbica, decomposição aeróbica e por perdas de efluentes, especialmente quando o teor de umidade é alto (Van Soest, 1994). Vários experimentos mostram que teores de MS inferiores a $25 \%$, bem como o aumento da temperatura, favorecem o desenvolvimento de fermentações secundárias na silagem (Muck, 1988; McDonald et al., 1991; Henderson, 1993).
O valor nutritivo de um volumoso é determinado em função de sua contribuição energética para atender as necessidades diárias de energia do animal e da quantidade consumida espontaneamente (Van Soest, 1994). A técnica de DIVMS, proposta por Tilley \& Terry (1963), tem sido a principal técnica para estimar o valor nutritivo de silagens, por demonstrar altas correlações com experimentos de digestibilidade in vivo. A DIVMS dos componentes físicos da planta (colmo, folhas e grãos) altera-se com o processo de ensilagem, de forma não análoga, observando-se, no componente grão, aumento significativo da DIVMS, enquanto, nos componentes colmo e folhas, os coeficientes permanecem praticamente inalterados.

Atenção especial deve ser dada à qualidade da fibra dos híbridos de sorgo, que apresentam comportamento agronômico diferenciado, quanto ao seu tipo e sua composição. De acordo com Van Soest (1994), os coeficientes de digestibilidade são influenciados pelos teores de lignina, taninos, FDA e celulose, e por suas interações.

O objetivo deste trabalho foi avaliar a qualidade da silagem do híbrido BR601, acrescida ou não de aditivos, através de alterações nos teores de MS, alterações nos teores de FDN, FDA, hemicelulose, celulose e lignina e variações na DIVMS, ao longo do processo fermentativo.

\section{Material e Métodos}

Foi utilizada a cultivar de sorgo forrageiro BR 601, da Embrapa Milho e Sorgo, e o experimento foi conduzido na área experimental dessa empresa, localizada no município de Sete Lagoas, Minas Gerais. A região situa-se a $19^{\circ}$ 
sul e $44^{\circ}$ oeste, a uma altitude média de $732 \mathrm{~m}$. De acordo com a classificação de Köppen, o clima é do tipo AW, ou seja, clima de savana, com inverno seco e temperatura média, no mês mais frio, acima de $18^{\circ} \mathrm{C}$. A cultivar foi plantada em janeiro de 1998, utilizando-se espaçamento de $0,70 \mathrm{~m}$ entre linhas. No plantio, realizouse adubação com 300 kg de 8-28-16 (NPK) e $100 \mathrm{~kg}$ de uréia em cobertura. A colheita ocorreu em maio de 1998, quando os grãos se apresentavam no estádio leitoso-pastoso. O corte foi manual, rente ao solo, e as plantas foram picadas em picadeira estacionária, ajustada para tamanho de partículas de aproximadamente $1 \mathrm{~cm}$. Os tratamentos foram: silagem sem aditivo (testemunha $-\mathrm{T}$ ), silagem com uréia $0,5 \%(\mathrm{U})$, silagem com carbonato de cálcio ( $\mathrm{CaCO} 3$ ) 0,5\% (CC), silagem com uréia mais $\mathrm{CaCO} 30,5 \%$ de cada $(\mathrm{U}+\mathrm{C})$ e silagem com inoculante bacteriano (IB), o qual é comercializado pelo nome de Silobac ${ }^{\circledR}$, produto à base de Lactobacillu. plantarum, Streptococcus faecium e Lactobacillus sp., possuindo $5,26 \times 10^{10}$ unidades formadoras de colônia/g.

Os aditivos foram incorporados no material, espalhado sobre lona de plástico, procedendo-se a mistura vigorosa. A uréia utilizada foi do tipo comercial granulada, e o $\mathrm{CaCO} 3$, do tipo P.A. O inoculante bacteriano foi utilizado na proporção de dois litros de solução, contendo $2 \mathrm{~g}$ do produto para cada tonelada de forragem.

Os silos utilizados foram cilindros de "PVC" com $10 \mathrm{~cm}$ de diâmetro e $50 \mathrm{~cm}$ de comprimento, fechados com tampa de "PVC" dotadas de válvulas tipo "Bunsen" e lacrados. Os silos foram pesados vazios e após serem lacrados. Após a ensilagem, os silos foram transportados para o Laboratório de Nutrição da Escola de Veterinária da UFMG, onde foram realizadas a abertura e as análises laboratoriais. Os silos foram abertos com um, três, cinco, sete, 14, 28 e 56 dias após a ensilagem e novamente pesados, para a determinação das alterações nos teores de MS durante o período de ensilagem, por diferença de peso.

O conteúdo foi posteriormente retirado e homogeneizado, sendo dividido em duas porções: a primeira, para extração do "suco da silagem", utilizando-se prensa hidráulica, e a segunda parte do material de cada silo foi colocada em estufa de ventilação forçada, a $62^{\circ} \mathrm{C}$, por 72 horas, para pré-secagem (Horwitz, 1980). Após esse período, as bandejas ficaram à temperatura ambiente, para estabilização da umidade do material, e foram pesadas, para determinação da matéria pré-seca, e seu conteúdo moído em peneiras de $1 \mathrm{~mm}$, em moinho tipo Wiley (Willey Mill Company). O material foi, em seguida, armazenado em frascos de plástico com tampa, para ser utilizado futuramente nas análises laboratoriais.

Nas amostras pré-secas das silagens, determinaram-se os teores de MS a $105^{\circ} \mathrm{C}$ (Horwitz, 1980), os componentes da parede celular - FDN, FDA, hemiceluloses, celulose e lignina (Van Soest et al., 1991) e a DIVMS, pela técnica descrita por Tilley \& Terry (1963).

Os dados foram avaliados por meio de análises de variância, utilizando-se o Sistema de Análises Estatísticas e Genéticas - SAEG (UFV, 2000). Adotou-se o delineamento inteiramente casualizado, em um esquema fatorial $5 \times 7$ (cinco tipos de silagem $\mathrm{x}$ sete tempos de abertura) e duas repetições por tratamento. Para a comparação das médias, foi empregado o teste SNK (Student Newman Keuls) a 5\% de probabilidade. Quando não houve efeito significativo da interação, do 
aditivo e do tempo de abertura, foi apresentada a média dos resultados obtidos.

\section{Resultados e Discussão}

Os valores referentes às perdas de MS da silagem de sorgo, acrescida ou não de aditivos, nos diferentes períodos de fermentação, são apresentados na Tabela 1 .

A silagem testemunha apresentou redução nos teores de MS semelhante, no decorrer dos dias de abertura. A silagem com $\mathrm{CaCO} 3$ também apresentou redução nos teores de MS entre os dias de abertura, porém só houve alteração significativa no dia $56(\mathrm{P}<0,05)$. Comparada à silagem testemunha, os valores de redução nos teores de MS da silagem com $\mathrm{CaCO} 3$ foram semelhantes entre os dois tratamentos apenas no primeiro dia de abertura, sendo superiores a partir do dia 3.

Os teores de MS das silagens nas quais foram adicionadas uréia como único aditivo mantiveram-se constantes ao longo do período experimental. Comparada à silagem testemunha, observou-se que, nos dias três, cinco e 14, as quedas nos teores de MS foram superiores. Nos demais dias, as porcentagens de quedas foram semelhantes entre os dois tratamentos.

$\mathrm{Na}$ silagem de sorgo em que foi adicionada uréia associada ao $\mathrm{CaCO} 3$, somente o primeiro dia de abertura diferiu dos demais, apresentando o menor valor de perda de MS. Em relação à silagem testemunha e às silagens com os demais aditivos, a silagens com uréia associada ao $\mathrm{CaCO} 3$ apresentaram valores de perdas semelhantes somente no primeiro dia de abertura. No restante do período experimental, as perdas nos teores de MS foram superiores a todos os demais tratamentos, apresentando, aos 56 dias, redução de 6,97\% da MS.

Essas variações nos teores de MS talvez estejam ligadas à alcalinização do meio, em função da presença de íons amônia, que impedem a queda do $\mathrm{pH}$ a valores que minimizem a atividade enzimática deletéria das plantas e dos microrganismos que são responsáveis pela quebra e perdas de nutrientes (Muck, 1988). Nessa situação, a ação conjunta dos íons cálcio e amônia provavelmente impediu, de forma

TABELA 1. Perdas de matéria seca (\%MS) das silagens do híbrido de sorgo BR 601 sem aditivos (T), tratadas com $0,5 \%$ de carbonato de cálcio (CC), 0,5\% de uréia (U), 0,5\% de uréia associada a $0,5 \%$ de carbonato de cálcio (U+CC) e inoculante bacteriano (IB), nos diferentes dias de abertura dos silos experimentais

\begin{tabular}{lccccccc}
\hline Silagens & \multicolumn{7}{c}{ Dia de abertura dos silos } \\
\cline { 2 - 8 } & $\mathbf{1}$ & $\mathbf{3}$ & $\mathbf{5}$ & $\mathbf{7}$ & $\mathbf{1 4}$ & $\mathbf{2 8}$ & $\mathbf{5 6}$ \\
\hline $\mathrm{T}$ & $1,07 \mathrm{Aa}$ & $1,27 \mathrm{Da}$ & $1,46 \mathrm{Da}$ & $1,55 \mathrm{Ca}$ & $1,69 \mathrm{Da}$ & $2,12 \mathrm{Da}$ & $2,30 \mathrm{Da}$ \\
$\mathrm{CC}$ & $1,40 \mathrm{Ab}$ & $2,84 \mathrm{Bb}$ & $2,98 \mathrm{Bb}$ & $3,46 \mathrm{Bb}$ & $3,52 \mathrm{Bb}$ & $3,66 \mathrm{Bb}$ & $4,45 \mathrm{Ba}$ \\
$\mathrm{U}$ & $1,35 \mathrm{Aa}$ & $2,19 \mathrm{Ca}$ & $2,33 \mathrm{Ca}$ & $2,08 \mathrm{Ca}$ & $2,49 \mathrm{Ca}$ & $2,51 \mathrm{CDa}$ & $3,01 \mathrm{Da}$ \\
$\mathrm{U}+\mathrm{CC}$ & $1,57 \mathrm{Ab}$ & $4,49 \mathrm{Aa}$ & $5,01 \mathrm{Aa}$ & $4,89 \mathrm{Aa}$ & $6,05 \mathrm{Aa}$ & $6,16 \mathrm{Aa}$ & $6,97 \mathrm{Aa}$ \\
$\mathrm{IB}$ & $1,12 \mathrm{Aa}$ & $1,98 \mathrm{Ca}$ & $2,19 \mathrm{Ca}$ & $2,16 \mathrm{Ca}$ & $2,48 \mathrm{Ca}$ & $2,87 \mathrm{CDa}$ & $3,65 \mathrm{Ca}$ \\
\hline
\end{tabular}

Médias seguidas de letras maiúsculas iguais na coluna e de letras minúsculas iguais na linha não diferem pelo teste SNK $(\mathrm{P}<0,05)$. CV=9,20\%. 
mais acentuada, a queda do $\mathrm{pH}$, promovendo maiores reduções nos teores de MS.

A silagem inoculada com bactérias não apresentou alteração na perda de MS ao longo do processo de fermentação. Porém, quando comparada à silagem testemunha, nos dias de abertura três, cinco, 14 e 56, as silagens inoculadas tiveram maiores reduções nos teores de MS. Nos dias um, sete e 28, as reduções foram semelhantes às da silagem testemunha.

Os resultados referentes aos teores de FDN e hemiceluloses podem ser visualizados na Tabela 2.

Para o tratamento sem aditivos, as concentrações de FDN oscilaram durante o período de ensilagem, diminuindo nos dias três, cinco, sete e 14, voltando nos dias 28 e 56 às concentrações semelhantes ao primeiro dia. Comparando-se o dia 56 com o dia um, não foi observada alteração nos teores de FDN, resultado este semelhante ao descrito por Borges et al. (1997).

Nas silagens de sorgo adicionadas de $\mathrm{CaCO}_{3}$, uréia e uréia associada ao $\mathrm{CaCO}_{3}$, não foram observadas alterações nas concentrações de FDN com o decorrer da fermentação $(\mathrm{P}<0,05)$, com exceção do dia 14 , no qual a silagem com $\mathrm{CaCO}_{3}$ apresentou o menor teor de FDN. Em relação à silagem testemunha, esses tratamentos não apresentaram diferenças nos teores de FDN, dentro dos tempos avaliados. Esses resultados estão de acordo com os obtidos por Vieira et al. (2004), que trabalharam com quatro cultivares de sorgo, sendo dois forrageiros (BR 601 e AG 2002) e dois de duplo propósito (BR 700 e BR 701),

TABELA 2. Concentrações de fibra em detergente neutro (FDN) e hemicelulose das silagens do híbrido de sorgo BR601 sem aditivos (T), tratadas com 0,5\% de carbonato de cálcio (CC), $0,5 \%$ de uréia $(\mathrm{U}), 0,5 \%$ de uréia associada a $0,5 \%$ de carbonato de cálcio $(\mathrm{U}+\mathrm{CC})$ e inoculante bacteriano (IB) nos diferentes dias abertura dos silos experimentais.

\begin{tabular}{|c|c|c|c|c|c|c|c|}
\hline \multirow[t]{2}{*}{ Silagens } & \multicolumn{7}{|c|}{ Dia de abertura dos silos } \\
\hline & 1 & 3 & 5 & 7 & 14 & 28 & 56 \\
\hline & \multicolumn{7}{|c|}{ FDN (\%MS) } \\
\hline $\mathrm{T}$ & $53,13 \mathrm{Aa}$ & $44,12 \mathrm{Ab}$ & $43,30 \mathrm{Ab}$ & $39,66 \mathrm{Ab}$ & $38,67 \mathrm{Ab}$ & $50,20 \mathrm{Aa}$ & $49,15 \mathrm{Aa}$ \\
\hline $\mathrm{CC}$ & $48,67 \mathrm{Aa}$ & $44,94 \mathrm{Aa}$ & $44,34 \mathrm{Aa}$ & $43,26 \mathrm{Aa}$ & $39,20 \mathrm{Ab}$ & $42,02 \mathrm{Aa}$ & $50,85 \mathrm{Aa}$ \\
\hline $\mathrm{U}$ & $52,33 \mathrm{Aa}$ & $47,98 \mathrm{Aa}$ & $46,96 \mathrm{Aa}$ & 48,76 Aa & $45,46 \mathrm{Aa}$ & $44,28 \mathrm{Aa}$ & $56,30 \mathrm{Aa}$ \\
\hline $\mathrm{U}+\mathrm{CC}$ & $47,20 \mathrm{Aa}$ & $50,76 \mathrm{Aa}$ & $51,30 \mathrm{Aa}$ & $47,21 \mathrm{Aa}$ & $45,08 \mathrm{Aa}$ & 45,79Aa & $53,50 \mathrm{Aa}$ \\
\hline \multirow[t]{2}{*}{ IB } & $54,54 \mathrm{Aa}$ & $47,83 \mathrm{Aa}$ & $48,13 \mathrm{Aa}$ & 45,08Aa & $41,74 \mathrm{Aa}$ & $43,00 \mathrm{Aa}$ & $53,55 \mathrm{Aa}$ \\
\hline & \multicolumn{7}{|c|}{ Hemicelulose (\%MS) } \\
\hline $\mathrm{T}$ & $31,65 \mathrm{Aa}$ & $23,20 \mathrm{Ab}$ & $21,23 \mathrm{Ab}$ & $19,26 \mathrm{Bb}$ & $19,68 \mathrm{Bb}$ & $21,36 \mathrm{Ab}$ & $25,55 \mathrm{Ab}$ \\
\hline $\mathrm{CC}$ & $25,12 \mathrm{Aa}$ & $24,49 \mathrm{Aa}$ & $24,23 \mathrm{Aa}$ & $21,51 \mathrm{Ba}$ & $20,64 \mathrm{Aba}$ & $19,60 \mathrm{Aa}$ & $24,75 \mathrm{Aa}$ \\
\hline $\mathrm{U}$ & $30,90 \mathrm{Aa}$ & $26,63 \mathrm{Aa}$ & $25,67 \mathrm{Aa}$ & 26,03Aa & $25,49 \mathrm{ABa}$ & $21,00 \mathrm{Aa}$ & $28,40 \mathrm{Aa}$ \\
\hline $\mathrm{U}+\mathrm{CC}$ & $26,42 \mathrm{Aa}$ & $28,96 \mathrm{Aa}$ & $30,29 \mathrm{Aa}$ & $28,60 \mathrm{Aa}$ & $26,61 \mathrm{Aa}$ & $23,25 \mathrm{Aa}$ & $29,00 \mathrm{Aa}$ \\
\hline IB & $27,70 \mathrm{Aa}$ & $24,18 \mathrm{Aa}$ & $24,63 \mathrm{Aa}$ & $22,61 \mathrm{ABa}$ & $22,14 \mathrm{ABa}$ & $21,07 \mathrm{Aa}$ & $27,25 \mathrm{Aa}$ \\
\hline
\end{tabular}

Médias seguidas de letras maiúsculas iguais na coluna e de letras minúsculas iguais na linha não diferem pelo teste SNK $(\mathrm{P}<0,05) . \mathrm{CV}=4,98 \%$ (FDN), CV=7,13\% (Hemicelulose). 
nas silagens de sorgo tratadas com $\mathrm{CaCO}_{3}$, mas diferem dos resultados obtidos nas silagens contendo uréia ou uréia associada ao $\mathrm{CaCO}_{3}$, que tiveram teores superiores ao controle.

As silagens contendo inoculante bacteriano não apresentaram alterações nos teores de FDN com o decorrer do tempo de ensilagem. Comparada à silagem testemunha, a inoculação não acarretou alterações nas concentrações de FDN, o que também foi observado por Vieira et al. (2004), provavelmente porque as bactérias do inoculante apresentaram maior afinidade por substratos solúveis. Esses autores trabalharam com o mesmo produto e a mesma dose utilizada no presente estudo.

Os teores de hemicelulose da silagem testemunha reduziram-se do primeiro $(31,65 \%)$ para o terceiro dia $(23,20 \%)$ $(\mathrm{P}<0,05)$, e do terceiro dia em diante se mantiveram estáveis, semelhante aos resultados de Borges et al. (1997), em dois dos quatro híbridos estudados. Os teores de hemicelulose das silagens com aditivos permaneceram constantes, sendo semelhantes do primeiro ao último dia.
Ocorreu efeito de tratamento apenas nos dias 7 e 14 de abertura, nos quais o tratamento testemunha apresentou os menores teores de hemicelulose $(\mathrm{P}<0,05)$. A utilização de inoculante bacteriano não afetou os teores de hemicelulose, com exceção nos dias 7 e 14, nos quais apresentou valores intermediários $(\mathrm{P}<0,05)$. A hemicelulose, é possivelmente, a principal fonte adicional de substrato para a fermentação lática, podendo ocorrer consumo de até $40 \%$ dessa fração (McDonald et al., 1991).

Na Tabela 3. são apresentados os resultados dos teores de celulose.

Não houve efeito dos tratamentos sobre o teor de celulose. A concentração média de celulose se manteve estável do primeiro até o sétimo dia de abertura. Houve efeito de dia de abertura $(\mathrm{P}<0,05)$, sendo que, no dia 14 , ocorreu redução no teor de celulose, voltando a aumentar e apresentando os maiores teores de celulose nos dias 28 e 56 de abertura.

Conforme Van Soest (1994), a celulose é tida como um carboidrato estável diante dos processos fermentativos. Entretanto, pode

TABELA 3. Concentrações de celulose (\%MS) das silagens do híbrido de sorgo BR601 sem aditivos (T), tratadas com $0,5 \%$ de carbonato de cálcio (CC), $0,5 \%$ de uréia (U), $0,5 \%$ de uréia associada a $0,5 \%$ de carbonato de cálcio (U+CC) e inoculante bacteriano (IB), nos diferentes dias abertura dos silos experimentais.

\begin{tabular}{lcccccccc}
\hline Silagens & \multicolumn{7}{c}{ Dia de abertura dos silos } \\
\cline { 2 - 9 } & $\mathbf{1}$ & $\mathbf{3}$ & $\mathbf{5}$ & $\mathbf{7}$ & $\mathbf{1 4}$ & $\mathbf{2 8}$ & $\mathbf{5 6}$ & Média \\
\hline $\mathrm{T}$ & $18,25 \mathrm{Aa}$ & $18,78 \mathrm{Aa}$ & $19,98 \mathrm{Aa}$ & $18,40 \mathrm{Aa}$ & $17,03 \mathrm{Aa}$ & $25,85 \mathrm{Aa}$ & $20,40 \mathrm{Aa}$ & $19,81 \mathrm{~A}$ \\
$\mathrm{CC}$ & $21,18 \mathrm{Aa}$ & $18,30 \mathrm{Aa}$ & $18,10 \mathrm{Aa}$ & $19,32 \mathrm{Aa}$ & $16,43 \mathrm{Aa}$ & $24,90 \mathrm{Aa}$ & $22,60 \mathrm{Aa}$ & $20,11 \mathrm{~A}$ \\
$\mathrm{U}$ & $19,19 \mathrm{Aa}$ & $19,42 \mathrm{Aa}$ & $19,08 \mathrm{Aa}$ & $20,38 \mathrm{Aa}$ & $17,76 \mathrm{Aa}$ & $20,79 \mathrm{Aa}$ & $24,70 \mathrm{Aa}$ & $20,19 \mathrm{~A}$ \\
$\mathrm{U}+\mathrm{CC}$ & $18,71 \mathrm{Aa}$ & $19,58 \mathrm{Aa}$ & $18,94 \mathrm{Aa}$ & $17,06 \mathrm{Aa}$ & $16,54 \mathrm{Aa}$ & $20,20 \mathrm{Aa}$ & $21,55 \mathrm{Aa}$ & $18,94 \mathrm{~A}$ \\
$\mathrm{IB}$ & $22,44 \mathrm{Aa}$ & $21,64 \mathrm{Aa}$ & $21,05 \mathrm{Aa}$ & $19,89 \mathrm{Aa}$ & $17,28 \mathrm{Aa}$ & $19,43 \mathrm{Aa}$ & $23,25 \mathrm{Aa}$ & $20,71 \mathrm{~A}$ \\
Média & $19,96 \mathrm{~b}$ & $19,54 \mathrm{~b}$ & $19,43 \mathrm{~b}$ & $19,01 \mathrm{~b}$ & $17,00 \mathrm{c}$ & $22,24 \mathrm{a}$ & $22,50 \mathrm{a}$ & - \\
\hline
\end{tabular}

Médias seguidas de letras maiúsculas iguais na coluna e de letras minúsculas iguais na linha não diferem pelo teste SNK $(\mathrm{P}<0,05) . \mathrm{CV}=10,19 \%$ 
ocorrer redução nos teores de celulose das silagens, devido às condições ácidas que promovem hidrólise, liberando glicose.

Os resultados referentes aos teores de FDA e lignina das silagens de sorgo estão presentes na Tabela 4.

Houve efeito de tratamento e dias de abertura dos silos sobre os teores de FDA $(\mathrm{P}<0,05)$. Observou-se que os teores médios de FDA foram semelhantes do primeiro $(21,84 \%$ da MS) até o sétimo dia de fermentação (21,19\% da MS). O dia 14 foi o que apresentou o menor valor médio de FDA $(19,12 \%$ da MS), em relação aos demais dias, e o maior teor de FDA foi observado no dia $56(25,68 \%$ da MS).
O valor médio de FDA da silagem testemunha $(22,32 \%$ da MS) foi superior ao valor médio encontrado por Borges et al. (1997), de 20,11\% da MS, e inferior ao de Rodrigues et al. (2002), com 36,33\% da MS. Não houve diferença nos teores de FDA das silagens tratadas com uréia e $\mathrm{CaCO}_{3}$ e a silagem testemunha. Assim, provavelmente, o nitrogênio adicional fornecido pela uréia e o cálcio proveniente do $\mathrm{CaCO}_{3}$ não favoreceram o metabolismo das bactérias fibrolíticas.

$\mathrm{O}$ teor médio de FDA da silagem com inoculante bacteriano $(23,19 \%$ da $\mathrm{MS})$ foi equivalente aos teores de FDA da silagem testemunha, da silagem tratada com $\mathrm{CaCO}_{3}$ e com uréia, porém superior à silagem tratada

TABELA 4. Concentrações de fibra em detergente ácido (FDA) e lignina das silagens do híbrido BR601 sem aditivos (T), tratadas com $0,5 \%$ de carbonato de cálcio (CC), 0,5\% de uréia (U), $0,5 \%$ de uréia associada a $0,5 \%$ de carbonato de cálcio $(\mathrm{U}+\mathrm{CC})$ e inoculante bacteriano (IB), nos diferentes dias abertura dos silos experimentais.

\begin{tabular}{lcccccccc}
\hline Silagens & \multicolumn{7}{c}{ Dia de abertura dos silos } \\
\cline { 2 - 9 } & $\mathbf{1}$ & $\mathbf{3}$ & $\mathbf{5}$ & $\mathbf{7}$ & $\mathbf{1 4}$ & $\mathbf{2 8}$ & $\mathbf{5 6}$ & Média \\
\hline $\mathrm{T}$ & $21,48 \mathrm{Aa}$ & $20,92 \mathrm{Aa}$ & $22,02 \mathrm{Aa}$ & $20,4 \mathrm{Aa}$ & $18,99 \mathrm{Aa}$ & $28,83 \mathrm{Aa}$ & $23,60 \mathrm{Aa}$ & $22,30 \mathrm{AB}$ \\
$\mathrm{CC}$ & $20,64 \mathrm{Aa}$ & $20,46 \mathrm{Aa}$ & $20,11 \mathrm{Aa}$ & $21,75 \mathrm{Aa}$ & $18,56 \mathrm{Aa}$ & $22,42 \mathrm{Aa}$ & $26,10 \mathrm{Aa}$ & $21,40 \mathrm{AB}$ \\
$\mathrm{U}$ & $21,42 \mathrm{Aa}$ & $21,35 \mathrm{Aa}$ & $21,29 \mathrm{Aa}$ & $22,72 \mathrm{Aa}$ & $19,97 \mathrm{Aa}$ & $23,28 \mathrm{Aa}$ & $27,90 \mathrm{Aa}$ & $22,50 \mathrm{AB}$ \\
$\mathrm{U}+\mathrm{CC}$ & $20,78 \mathrm{Aa}$ & $21,80 \mathrm{Aa}$ & $21,01 \mathrm{Aa}$ & $18,61 \mathrm{Aa}$ & $18,47 \mathrm{Aa}$ & $22,53 \mathrm{Aa}$ & $24,50 \mathrm{Aa}$ & $21,00 \mathrm{~B}$ \\
$\mathrm{IB}$ & $24,85 \mathrm{Aa}$ & $23,64 \mathrm{Aa}$ & $23,51 \mathrm{Aa}$ & $22,46 \mathrm{Aa}$ & $19,6 \mathrm{Aa}$ & $21,93 \mathrm{Aa}$ & $26,30 \mathrm{Aa}$ & $23,20 \mathrm{~A}$ \\
Média & $21,84 \mathrm{bc}$ & $21,64 \mathrm{bc}$ & $21,60 \mathrm{bc}$ & $21,19 \mathrm{c}$ & $19,12 \mathrm{~d}$ & $23,80 \mathrm{~b}$ & $25,68 \mathrm{a}$ & \\
& & & & Lignina & $\mathbf{7} \mathbf{M S})$ & & & \\
& & & & & & & \\
\hline $\mathrm{T}$ & $2,24 \mathrm{Aa}$ & $2,15 \mathrm{Aa}$ & $2,08 \mathrm{Aa}$ & $1,99 \mathrm{Aa}$ & $1,96 \mathrm{Aa}$ & $2,99 \mathrm{Aa}$ & $3,20 \mathrm{Aa}$ & $2,52 \mathrm{~A}$ \\
$\mathrm{CC}$ & $2,37 \mathrm{Aa}$ & $2,16 \mathrm{Aa}$ & $2,01 \mathrm{Aa}$ & $2,43 \mathrm{Aa}$ & $2,14 \mathrm{Aa}$ & $2,53 \mathrm{Aa}$ & $3,50 \mathrm{Aa}$ & $2,45 \mathrm{~A}$ \\
$\mathrm{U}$ & $2,23 \mathrm{Aa}$ & $1,93 \mathrm{Aa}$ & $2,22 \mathrm{Aa}$ & $2,34 \mathrm{Aa}$ & $2,21 \mathrm{Aa}$ & $2,49 \mathrm{Aa}$ & $3,20 \mathrm{Aa}$ & $2,37 \mathrm{AB}$ \\
$\mathrm{U}+\mathrm{CC}$ & $2,07 \mathrm{Aa}$ & $2,23 \mathrm{Aa}$ & $2,07 \mathrm{Aa}$ & $1,55 \mathrm{Aa}$ & $1,94 \mathrm{Aa}$ & $2,32 \mathrm{Aa}$ & $2,95 \mathrm{Aa}$ & $2,16 \mathrm{~B}$ \\
$\mathrm{IB}$ & $2,42 \mathrm{Aa}$ & $1,99 \mathrm{Aa}$ & $2,45 \mathrm{Aa}$ & $2,58 \mathrm{Aa}$ & $2,33 \mathrm{Aa}$ & $2,51 \mathrm{Aa}$ & $3,05 \mathrm{Aa}$ & $2,47 \mathrm{~A}$ \\
Média & $2,46 \mathrm{~b}$ & $2,09 \mathrm{c}$ & $2,17 \mathrm{c}$ & $2,18 \mathrm{c}$ & $2,11 \mathrm{c}$ & $2,57 \mathrm{~b}$ & $3,18 \mathrm{a}$ & \\
\hline
\end{tabular}

Médias seguidas de letras maiúsculas iguais, na coluna, e de letras minúsculas iguais, na linha, não diferem pelo teste SNK $(\mathrm{P}<0,05) . \mathrm{CV}=8,93 \%$ (FDA), $\mathrm{CV}=12,17 \%$ (Lignina). 
com a associação uréia e $\mathrm{CaCO}_{3}$. Embora tenha trabalhado com o mesmo inoculante bacteriano do presente estudo, Vieira et al. (2004) observaram aumento nos teores de FDA, provavelmente devido às bactérias presentes no inoculante terem apresentado pouca afinidade pela parede celular, consequentemente, ocorrendo redução dos componentes solúveis, elevando proporcionalmente os teores das frações fibrosas.

Ocorreram variações nos teores médios de lignina com o avançar do período de ensilagem. Houve declínio do primeiro (2,46\% da MS) para o terceiro dia (2,09\% da MS), estabilização até o dia 14 (2,11\% da MS), com posterior elevação dos teores de lignina nos dias 28 e $56(2,57 \%$ e $3,18 \%$ da $\mathrm{MS}$, respectivamente) $(\mathrm{P}<0,05)$.

A utilização de $\mathrm{CaCO}_{3}$, uréia e inoculante bacteriano não acarretou mudanças nos teores de lignina em relação à silagem testemunha. Quanto à utilização de uréia associada ao $\mathrm{CaCO}_{3}$, verificou-se redução nos teores de lignina em relação à silagem testemunha, ao $\mathrm{CaCO}_{3}$ e ao inoculante bacteriano.

Os teores da DIVMS das silagens de sorgo com ou sem aditivos, nos diferentes dias de abertura, estão na Tabela 5.
A silagem testemunha apresentou valores estáveis de DIVMS com o decorrer do período de ensilagem, havendo redução apenas no dia 28. Borges et al. (1997) e Porto et al. (2006) também observaram que os valores de DIVMS permaneceram estáveis ao longo do processo fermentativo.

No tratamento com $\mathrm{CaCO} 3$ não ocorreram alterações nos valores de DIVMS no decorrer do período de ensilagem. A DIVMS permaneceu semelhante à silagem testemunha até o dia 56 , com exceção no dia de abertura 28 , no qual foi superior.

No tratamento de uréia associada ao $\mathrm{CaCO}_{3}$ e naquele contendo somente uréia também não ocorreram alterações nos valores de DIVMS ao longo do período de ensilagem. Comparando as silagens com e sem aditivos, observa-se que os teores de DIVMS foram semelhantes em praticamente todos os dias de abertura, diferindo somente no dia $28(\mathrm{P}<0,05)$, no qual a silagem testemunha apresentou redução em relação às demais. Os valores de DIVMS da silagem com inoculante bacteriano permaneceram estáveis ao longo dos dias de fermentação e, comparados aos da silagem

TABELA 5. Valores da digestibilidade "in vitro" da matéria seca (\%MS) das silagens do híbrido BR 601 sem aditivos (T), tratadas com $0,5 \%$ de carbonato de cálcio (CC), 0,5\% de uréia (U), $0,5 \%$ de uréia associada a $0,5 \%$ de carbonato de cálcio (U+CC) e inoculante bacteriano (IB), nos diferentes dias abertura dos silos experimentais.

\begin{tabular}{lccccccc}
\hline Silagens & \multicolumn{7}{c}{ Dia de abertura dos silos } \\
\hline $\mathrm{T}$ & $\mathbf{1}$ & $\mathbf{3}$ & $\mathbf{5}$ & $\mathbf{7}$ & $\mathbf{1 4}$ & $\mathbf{2 8}$ & $\mathbf{5 6}$ \\
$\mathrm{CC}$ & $58,22 \mathrm{Aa}$ & $54,97 \mathrm{Aa}$ & $61,22 \mathrm{Aa}$ & $58,60 \mathrm{Aa}$ & $62,88 \mathrm{Aa}$ & $46,38 \mathrm{Cb}$ & $60,92 \mathrm{Aa}$ \\
$\mathrm{U}$ & $57,45 \mathrm{Aa}$ & $59,88 \mathrm{Aa}$ & $66,53 \mathrm{Aa}$ & $55,92 \mathrm{Aa}$ & $64,85 \mathrm{Aa}$ & $52,23 \mathrm{Ba}$ & $54,79 \mathrm{Aa}$ \\
$\mathrm{U}+\mathrm{CC}$ & $59,33 \mathrm{Aa}$ & $61,15 \mathrm{Aa}$ & $63,88 \mathrm{Aa}$ & $55,60 \mathrm{Aa}$ & $57,55 \mathrm{Aa}$ & $57,88 \mathrm{ABa}$ & $58,92 \mathrm{Aa}$ \\
$\mathrm{IB}$ & $59,17 \mathrm{Aa}$ & $62,10 \mathrm{Aa}$ & $67,05 \mathrm{Aa}$ & $57,20 \mathrm{Aa}$ & $62,33 \mathrm{Aa}$ & $59,82 \mathrm{ABa}$ & $63,58 \mathrm{Aa}$ \\
\hline
\end{tabular}

Médias seguidas de letras maiúsculas iguais, na coluna, e de letras minúsculas iguais, na linha, não diferem pelo teste SNK $(\mathrm{P}<0,05)$. CV=4,96\%. 
testemunha, diferiram apenas nos dias de abertura cinco e 28. Esse resultado concorda com o observado por Stehling (2001) e Rodrigues et al. (2002), que avaliaram silagens de girassol e sorgo acrescidas de inoculantes bacterianos, respectivamente.

Gonçalves et al. (1998), trabalhando com silagens de milho com $0,5 \%$ de uréia, e Porto et al. (2006), trabalhando com silagem de girassol com a mesma proporção desse aditivo, observaram que a uréia não proporcionou alteração da DIVMS com o período de ensilagem. Quanto ao uso de $\mathrm{CaCO}_{3}$ associado à uréia, Vieira et al. (2004) relatou aumento na DIVMS na silagem de três genótipos de sorgo, em relação à silagem testemunha, que foi, em média, $62,7 \%$ da MS para a silagem com uréia associada a $\mathrm{CaCO}_{3}$ e $58,1 \%$ da MS para a silagem testemunha.

O valor da DIVMS do dia 56 (60,92\% da MS) permite classificar a silagem testemunha, assim como as silagens com aditivos, como de boa qualidade, segundo a classificação de Borges et al. (1997) e Paiva (1976).

\section{Conclusões}

O híbrido de sorgo forrageiro BR 601 apresentou-se adequado ao processo de ensilagem, em relação aos parâmetros estudados.

Os aditivos empregados neste experimento não promoveram alterações consistentes sobre as frações fibrosas, perda de matéria seca e digestibilidade in vitro da matéria seca das silagens.

\section{Literatura Citada}

BORGES, A. L. C. C.; GONÇALVES, L. C.; RODRIGUEZ, N. M. et al. Qualidade das silagens de híbridos de sorgo com diferentes teores de tanino e de umidade no colmo. Arquivo Brasileiro de Medicina Veterinária e Zootecnia, Belo Horizonte, v. 49, p. 441452, 1997.

GONÇALVES, L. C.; BORGES, A. L. C. C.; RODRIGUEZ, N. M. et al. Silagens de sorgo de porte alto com diferentes teores de tanino e de umidade no colmo.IV- Digestibilidade in vitro da matéria seca. Arquivo Brasileiro de Medicina Veterinária e Zootecnia, Belo Horizonte, v. 50, p. 167-170, 1998.

GONÇALVES, L. C.; PIRES, D. A. A; CASTRO, G. H. D. Algumas considerações sobre silagens de sorgo. In: SIMPÓSIO DE NUTRIÇÃO DE GADO DE LEITE, 3., 2005. Belo Horizonte. Anais... Belo Horizonte, 2005. p.5-18.

HENDERSON, N. Silage additives. Animal Feed Science and Technology, Amsterdam, v. 45, p. 35-56, 1993.

HORWITZ, W. (Ed.). Official methods of analysis of the Association of Official Analytical Chemists. 13. ed. Washington: AOAC, 1980. 1018 p.

McDONALD, P.; HENDERSON, A.; HERON, S. J. E. The biochemistry of the silage, 2 nd. ed.. Marlow: Chalcombe Publications, 1991. $340 \mathrm{p}$.

MOLINA, L. R.; GONÇALVES, L. C.; RODRIGUEZ, N. M. et al.Qualidade das silagens de seis genótipos de sorgo [Sorghum bicolor (L.) Moench] em diferentes estádios de maturação. Arquivo Brasileiro de Medicina 
Veterinária e Zootecnia, Belo Horizonte, v. 54, p. 159-168, 2002.

MUCK, R.E. Factors influencing silage quality and their implications for management. Journal Dairy Science, Champaign, v. 71, p. 2992-3002, 1988.

PAIVA, J. A. J. Qualidade da silagem da região Metalúrgica de Minas Gerais. 1976, 85 f. Dissertação (Mestrado) - Escola de Veterinária, Universidade Federal de Minas Gerais, Belo Horizonte, MG.

PEDROSO, A. F.; FREITAS, A .R.; SOUZA, G. B. Efeito de inoculante bacteriano sobre a qualidade da silagem e perda de matéria seca durante a ensilagem do sorgo. Revista Brasileira de Zootecnia, Viçosa, MG, v. 29, p. 48-52, 2000.

PORTO. P. P.; SALIBA, E. O. S.; GONÇALVES, L. C. et al. Frações da parede celular e digestibilidade "in vitro" da matéria seca de três genótipos de girassol ensilados com aditivos. Arquivo Brasileiro de Medicina Veterinária e Zootecnia, Belo Horizonte, v. 58, p. 99-107, 2006.

RODRIGUES, P.H.M.; SENATORE, A.L.; ANDRADE, S.J.T. et al. Efeitos da adição de inoculantes microbianos sobre a composição bromatológica e perfil fermentativo da silagem de sorgo produzida em silos experimentais. Revista Brasileira de Zootecnia, Viçosa, MG, v. 31, p. 2373-2379, 2002.

STEHLING, C.A.V. Avaliação da qualidade das silagens de quatro cultivares de girassol contendo aditivos. 2001. 64f. Dissertação (Mestrado)-Escola de Veterinária, Universidade Federal de Minas Gerais, Belo Horizonte.

TILLEY, J.M.A.; TERRY, R.A. Two stage technique for the "in vitro"digestion of forage crops. Journal British Grassland Society, Oxford, v. 18, p. 104-111, 1963.

UNIVERSIDADE FEDERAL DE VIÇOSA. SAEG- Sistema de análises estatísticas e genéticas (manual do usuário). Versão 8.0. Viçosa, MG, 2000. 142 p.

VAN SOEST, P. J. Nutritional ecology of the ruminant. 2nd. ed. Ithaca: Cornell University, 1994. $476 \mathrm{p}$.

VAN SOEST, P. J. ROBERTSON, J. B., LEWIS, B.A. Methods for dietary fiber, neutral detergent fiber, and non starch polysaccharides in relation to animal nutrition. Journal Dairy Science, Champaign, v. 74, p. 3583-3597, 1991.

VIEIRA, F. A. P.; BORGES, I.; STEHLING, C. A. V et al. Qualidade de silagens de sorgo com aditivos. Arquivo Brasileiro de Medicina Veterinária e Zootecnia, Belo Horizonte, v. 56, p.764-772, 2004.

ZAGO, C. P. Utilização do sorgo na alimentação de ruminantes. In: EMBRAPA. CENTRO NACIONAL DE PESQUISA DE MILHO E SORGO. Manejo cultural do sorgo para forragem. Sete Lagoas, 1992. p. 9-26. (EMBRAPA-CNPMS.Circular Técnica, 17). 